DOI dx.doi.org/10.24866/7444-4707-6/265-276

А.Б. Гынинова, Б-М.Н. Гончиков, Н.В. Барановский, А.В. Базаров, Ж.Б-М. Гончиков

\title{
ВЛИЯНИЕ ЛЕСНЫХ ПОЖАРОВ НА ПОЧВЕННЫЙ ПОКРОВ СОСНОВЫХ БОРОВ ПРИБАЙКАЛЬЯ*
}

Леса Республики Бурятия занимают площадь 27.0 млн. га или 80.3\% ее общей земельной площади. Они выполняют углеродную и другие экологические функции, и в том числе водоохранную, что особенно важно для Прибайкалья [Гынинова, Балсанова и др., 2006]. В то же время, леса Бурятии отличаются высокой природной пожарной опасностью со средним классом 2.5. Наиболее опасными в пожарном отношении являются сосновые боры и хвойные молодняки, которые занимают $49.8 \%$ от общей площади, занимаемой хвойными насаждениями или $28.4 \%$ от площади лесного фонда республики [Итоги пожароопасного сезона..., 2014]. Известно, что в Бурятии в последние годы возросло количество пожаров, и увеличились площади, пройденные пожарами.

Целью является исследование физико-химических и химических свойств и микроморфологического строения почв сосновых лесов на песчаных озерно-речных террасах в юго-западном Прибайкалье и их изменений после низовых и верховых пожаров.

Район исследования относится к Прибайкальской гольцово-горнотаежной и котловинной физико-географической провинции. Климат района резко континентальный, несколько смягчающийся влиянием оз. Байкал [Жуков, 1960]. Годовая сумма осадков составляет 400 мм, основная часть их выпадает во второй половине лета. Среднегодовая температура отрицательная $\left(-1^{\circ} \mathrm{C}\right)$, температура января: средняя $-25^{\circ} \mathrm{C}$, минимальная $-40^{\circ} \mathrm{C}$, температура июля: средняя $+21^{\circ} \mathrm{C}$, максимальная $+36^{\circ} \mathrm{C}$.

Объектами исследования послужили почвы сосновых боров, формирующихся на песчаных террасах в восточной части Селенгинского дель-

\footnotetext{
"Работа выполнена в рамках проекта АААА-А17-117011810038-7 и при поддержке грантов РФФИ № 17-29-05093, №18-45-0 30022 р_а, № 18-45-030033.
} 
тового района. Изучались почвы на участках, не измененных пожаром, пройденных низовым и верховым лесными пожарами 15 лет назад.

Морфологическое строение. Разрез 15 - 11 Д заложен на участке, не измененном пожаром. Растительность представлена хорошо развитым сосновым древостоем высотой 25-30 м, с сомкнутостью крон 0.7-0.8 и обильным подростом. Напочвенный покров лишайниково-брусничный с отдельными экземплярами разнотравья, представленного прострелом и осокой стоповидной и проективным покрытием $\sim 20 \%$. В кустарниковом ярусе - единично рододендрон даурский. Лесная подстилка состоит в основном из остатков хвои, степень разложения которой в верхней части слабая и увеличивается к нижней.

Горизонт We песчаный, буровато-светло-серый (10YR 5/2), в нижней части - обнаруживается оподзоливание (прерывистая осветленнная полоca) (10YR 6/2). Структура непрочно-комковатая, корней очень мало. Подгумусовый горизонт $\mathrm{C}$ “ представляет собой рассыпчатый хорошо сортированный песок желтовато-бурого с охристым оттенком цвета (7.5YR 6/4) с включением древесных корней. Горизонт пересекают проникающие из осветленных участков горизонта We, вертикальные, извилистые светлые полосы шириной $\sim 1$ см, образовавшиеся, по всей вероятности, по ходам корней. Ниже выделяется горизонт $\mathrm{C} 1{ }^{\prime} \mathrm{f}$, в котором охристый оттенок становится несколько интенсивней (7.5YR 5/4). Горизонт C2 ${ }^{*}$ имеет признаки почвообразующей породы, общие для всех исследуемых разрезов: плотноватое сложение и устойчивую светло-бурую (10YR 6/4) окраску. По строению профиля почвы близки к псаммоземам. Однако, учитывая наличие, наряду с мощной подстилкой, слаборазвитого гумусового горизонта, очевидно, почву следует отнести к типу «псаммоземы гумусовые». Принимая во внимание осветленность нижней части гумусового горизонта и вертикальные полосы в горизонте C`ㄷ следует почвы отнести к подтипу оподзоленных. Строение профиля почвы имеет формулу $\mathrm{O}(0-4)$ $\mathrm{We}(4-9)-\mathrm{C}{ }^{*} \mathrm{f}(9-33)-\mathrm{C} 1{ }^{\circ} \mathrm{f}(33-70)-\mathrm{C} 2{ }^{*}(70-110)$.

На участке, пройденном 15 лет назад низовым пожаром, сосновый лес редкостойный, травянисто-брусничный. Высота древостоя 25 метров, возраст - 50-60 лет. В разнотравье осока стоповидная, прострел. Проективное покрытие напочвенного покрова 10 - $15 \%$, очень неравномерное. При устойчивых низовых пожарах высота пламени достигает 2,5 м, температура горения $\sim 700{ }^{\circ} \mathrm{C}$ [Воробьев, 2004]. Это приводит к частичному 
выгоранию и частичному обугливанию органического вещества, обгоранию корней и коры деревьев, полному сгоранию подроста и подлеска, важно также то, что при этом древостой сохраняется и происходит очищение леса от горючих материалов.

Лесная подстилка почвы, трансформированной низовым пожаром, спустя 15 лет состоит из неразложившегося опада, и от темно-серого до черного (10YR 4/1-3/1-2/1) пирогенного мульчированного слоя, который мало изменился за этот срок. Гумусовый горизонт имеет темно-серый цвет $(7.5 \mathrm{YR} 5 / 2)$ в связи с присутствием углистых веществ. Появление грибного мицелия в нижней части подстилки свидетельствует о гумификации органического вещества с образованием кислых форм. В горизонте

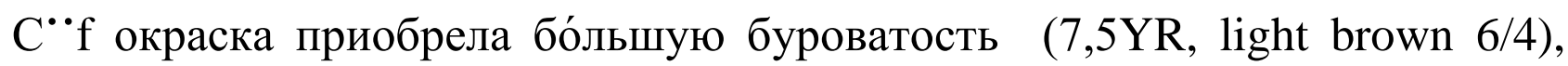
либо в связи с активизацией вертикальной миграции железа с подвижными формами гумуса, либо под влиянием высоких температур и окисления железа. Нижележащие горизонты идентичны по окраске (7,5YR, reddish yellow 6/67,5YR, reddish yellow 6/8) с непирогенной почвы. В целом учитываю высокую степень сохранности углистых горизонтов и приобретении горизонтом C * f буроватой окраски позволяет предложить выделение на уровне подтипа псаммозёмов постпирогенных в отделе Слаборазвитые. Почвенный профиль приобрел строение О(0-1)-Opir(1-2)-AYpir(2-8)$\mathrm{C} \cdot \mathrm{f}(8-37)-\mathrm{C} 1{ }^{*}(37-60)-\mathrm{C} 2 \cdot \cdot(60-112)$.

На участке, пройденном 15 лет назад верховым пожаром, зрелый древостой отсутствует, возобновление леса в отдельных местах еще не начиналось, либо появилась редкая сосновая поросль. Напочвенный покров бруснично-травянистый мохово-лишайниковый: брусника куртинами, в разнотравье прострел, вейник, полынь. Мох коричневый (Ceratodon), лишайники родов кладония и цетрария. Проективное покрытие напочвенного покрова составляет лишь 5 \%. При верховых пожарах температура горения достигает $900-1200{ }^{\circ} \mathrm{C}$, лес выгорает полностью, процесс почвообразования начинается с «0»-момента. На поверхности почвы поселяются лишайники, которые постепенно образуют тонкую корочку, скрепленную ризоидами. Для активизации лесовозобновления проведено рыхление граблями (разрушение корочки). Горизонт W - маломощная песчаная корочка буровато-темно-серой окраски (7.5YR 4/1), с хрупкой непрочно-комковатой, скрепленной корешками структурой. Ниже, до глубины 8 см, наблюдается прокрашенность почвенной массы в тусклый бу- 
роватый цвет (7.5YR 6/3), аналогичный цвету горизонта C'•f постпирогенной почвы р. 13-11Д.

Морфологическое строение профиля позволяет предполагать, что после уничтожения лесной растительности и органического вещества почвы верховым пожаром углистого слоя не образуется, или он выдувается, и почвообразование начинается с «0-момента». Возобновление лесной растительности слабое. В этих условиях за 15 лет отмечается образование прерывистого маломощного (1 см) горизонта $\mathrm{W}$ и буроватого подгумусового горизонта $\mathrm{C}$ • f, что позволяет предполагать принадлежность почвы к отделу слаборазвитых и соответствует профилю псаммозема гумусового. Выявленные особенности морфологического строения свидетельствуют о том, что период возврата к фоновой почве может растянуться на долгое время, особенно в условиях аридизации климата. Профиль почвы имеет строение $\mathrm{W}(0-1)-\mathrm{C} \cdot \mathrm{f}(1-8)-\mathrm{C} 1{ }^{*}(8-41)-\mathrm{C} 2 \cdot(41-102)$.

Исследование морфологического строения почв сосновых боров Селенгинского дельтового района показало, что на песчаных переработанных ветром террасах почвы формируются под влиянием процессов активного образования лесной подстилки, слабо выраженных гумусонакопления и оподзоливания [Гынинова, Корсунов, 2006]. Согласно Классификации почв России, описанные почвы относятся к типу псаммоземы, подтипу оподзоленные отдела Слаборазвитые. После низового пожара подстилка и гумусовый горизонты обугливаются и приобретают темно-серый цвет. Одновременно, получает некоторое развитие альфегумусовый процесс, обусловливающий образование горизонта $\mathrm{C}$ “的, имеющего мощность 29 см. В целом происходит изменение верхней и средней части профиля псаммоземов, которые, учитывая хорошо сохраняющиеся признаки пирогенеза следует отнести к постпирогенным в качестве подтипа псаммоземов гумусовых [Классификация и диагностика почв России, 2004]. После верхового пожара почва начала развиваться с «0»-момента, за 15 лет произошло образование зоны аккумуляции гумуса (W) мощностью всего $1 \mathrm{~cm}$, отмечается также некоторое ожелезнение с образованием маломощного (7 cм) горизонта C`‥ Почвообразовательные процессы сильно заторможены, почвы слаборазвиты и должны, очевидно, принадлежать типу псаммоземы в отделе Слаборазвитые, подтипу иллювиально-ожелезненные. 
Физические свойства. Исследование гранулометрического состава почв сосновых боров (табл. 1) обнаруживает их связно-песчаный состав, при рыхлопесчаной почвообразующей породе. Для почв и пород характерна высокая степень сортированности со значительным преобладанием фракции мелкого песка. Содержание илистой фракции весьма низкое. Во всех исследованных разрезах оно имеет наименьшее значение в поверхностном горизонте и слабо возрастает вниз по профилю, захватывая верхнюю часть почвообразующей породы, что указывает на некоторый вынос тонкой фракции вниз по профилю.

Удельный вес твердой фазы (табл. 2) непирогенной и пройденной низовым пожаром почвы имеет более высокие значения в почвообразующей породе. После верхового пожара в поверхностном горизонте почвы наблюдается довольно резкое увеличение этого показателя в горизонте $\mathrm{C}$ •*f под пирогенной корочкой, очевидно, в результате некоторой трансформации минералов под влиянием высоких температур.

Таблица 1

\section{Гранулометрический состав почв}

\begin{tabular}{|c|c|c|c|c|c|c|c|c|c|c|}
\hline \multirow[b]{2}{*}{$\begin{array}{c}\text { Горзонт, } \\
\text { глубина, см }\end{array}$} & \multirow[b]{2}{*}{$\begin{array}{c}\mathrm{W}_{\Gamma}, \\
\%\end{array}$} & \multirow[b]{2}{*}{$\begin{array}{c}\text { Удель } \\
\text { ный } \\
\text { вес }\end{array}$} & \multicolumn{8}{|c|}{ Содержание фракций, \% (размер частиц, мм) } \\
\hline & & & $\begin{array}{l}1.0- \\
0.25\end{array}$ & $\begin{array}{c}0,25- \\
0.05\end{array}$ & $\begin{array}{c}0.05- \\
0.01\end{array}$ & $\begin{array}{l}0.01- \\
0.005\end{array}$ & $\begin{array}{c}0.005 \\
- \\
0.001\end{array}$ & $\begin{array}{c}<0.00 \\
1\end{array}$ & 1 & $>0$ \\
\hline \multicolumn{11}{|c|}{ Разрез 15 - 11 Д. (Сосновый лес, без признаков пирогенеза) } \\
\hline We ( & 0.67 & 2.62 & 7.94 & 71.90 & 10.95 & 2.18 & 3.72 & 3.31 & 9.21 & 0.13 \\
\hline $\mathrm{C}^{* *}$ & & 53 & 10 & 3 & 11.66 & & 3.45 & 0 & 1 & 0.3 \\
\hline $\mathrm{C} 1{ }^{\circ} \mathrm{f}(3$ & 0.61 & 2.63 & 48 & 7.02 & 5.19 & 79 & 1.31 & 5.21 & 31 & 0.6 \\
\hline $\mathrm{C} 2$ & 0.55 & 2.68 & 11.49 & 80.86 & 4.08 & 0.42 & 0.48 & 2.67 & 3. & 90.4 \\
\hline \multicolumn{11}{|c|}{ Разрез 13 - 11Д. (Сосновый лес, пройденный низовым пожаром) } \\
\hline AYpil & 0.84 & 2.61 & 11.63 & 63.70 & 15.76 & 2.24 & 4.55 & 2.12 & 8.91 & 91.09 \\
\hline $\mathrm{C}^{* \cdot}$ & 25 & 2.63 & .81 & 67.77 & 8.84 & 1.82 & 4.88 & 2.88 & 9.58 & $\overline{90.42}$ \\
\hline $\mathrm{C} 1{ }^{*} \mathrm{f}($ & 0.37 & 2.74 & 26.53 & 65.27 & 2.92 & 0.98 & 0.40 & 3.90 & 5.28 & 94.72 \\
\hline $\mathrm{C} 2{ }^{*}(60-112)$ & 0.14 & 2.71 & 25.32 & 69.40 & 2.26 & 0.08 & 0.22 & 2.72 & 3.02 & 99.92 \\
\hline \multicolumn{11}{|c|}{ Разрез 14 - 11 Д. (Сосновый лес, пройденный верховым пожаром) } \\
\hline $\mathrm{W}(0-1)$ & 0.83 & 2.62 & 12.64 & 67.85 & 11.29 & 2.34 & 3.78 & 2.10 & 8.22 & 91.78 \\
\hline $\mathrm{C} \cdot \mathrm{f}(1-8)$ & .48 & 2.76 & 11.99 & 76.67 & 1.00 & 3.56 & 3.46 & 3.32 & 10.34 & 89.66 \\
\hline $\mathrm{C} 1{ }^{\circ}(8-41)$ & 0.36 & 68 & 15.15 & 71.81 & 6.58 & 1.38 & 1.92 & 3.16 & 6.46 & 93.54 \\
\hline $\mathrm{C} 2{ }^{*}(41-102)$ & 0.18 & 2.71 & 17.37 & 71.61 & 3.48 & 0.04 & 1.02 & 2.48 & 3.54 & 96.4 \\
\hline
\end{tabular}


Плотность сложения почвы в сосновом бору, не измененном пожаром, закономерно и постепенно возрастает с глубиной и варьирует в пределах $1.24-1.61$ г/см³ [Качинский, 1965]. Аналогично изменяется и плотность почвы, пройденной верховым пожаром. В почвах, трансформированных низовым пожаром, в горизонте C’ $\mathrm{f}$ под гумусовым горизонтом на глубине 8 см плотность резко возрастает.

Таблица 2

\section{Водно-физические свойства почв}

\begin{tabular}{|c|c|c|c|c|c|c|}
\hline $\begin{array}{l}\text { Горизонт. } \\
\text { глубина. см }\end{array}$ & $\mathrm{W}, \%$ & $\begin{array}{c}\text { Удель- } \\
\text { ный вес } \\
\text { твердой } \\
\text { фазы, } \\
\text { г/см }\end{array}$ & 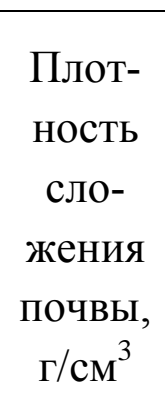 & $\begin{array}{c}\text { Водопро } \\
\text { ницаемо } \\
\text { сть, мм } \\
\text { вод.ст./ч }\end{array}$ & $\begin{array}{c}\text { Наим } \\
\text { ень- } \\
\text { шая } \\
\text { вла- } \\
\text { гоем- } \\
\text { кость, } \\
\%\end{array}$ & $\begin{array}{c}\text { Пороз } \\
\text { роз- } \\
\text { ность, } \\
\%\end{array}$ \\
\hline \multicolumn{7}{|c|}{ Разрез 15 - 11 Д. (Сосновый лес, без признаков пирогенеза) } \\
\hline $\mathrm{O}(0-4)$ & - & - & - & 236.84 & $\begin{array}{c}109.5 \\
9\end{array}$ & - \\
\hline We (4-9) & 0.67 & 2.62 & 1.24 & 228.2 & 37.54 & 52.67 \\
\hline$C \cdot \cdot f(9-33)$ & 0.55 & 2.63 & 1.39 & 225.0 & 18.1 & 47.15 \\
\hline $\mathrm{C} 1{ }^{\circ} \mathrm{f}(33-70)$ & 0.61 & 2.63 & 1.43 & 998.22 & 17.66 & 45.63 \\
\hline $\mathrm{C} 2{ }^{*}(70-110)$ & 0.55 & 2.68 & 1.61 & 1570.64 & 18.27 & 39.92 \\
\hline \multicolumn{7}{|c|}{ Разрез 13 - 11Д. (Сосновый лес, пройденный низовым пожаром) } \\
\hline AY (2-8) & 0.84 & 2.61 & 1.22 & 216.88 & 35.51 & 53.26 \\
\hline$C \cdot \cdot f(8-37)$ & 0.25 & 2.63 & 1.60 & 905.78 & 16.74 & 39.16 \\
\hline $\mathrm{C} 1{ }^{*}(37-60)$ & 0.37 & 2.74 & 1.57 & 1473.53 & 14.16 & 42.7 \\
\hline $\mathrm{C} 2 \cdot(60-112)$ & 0.14 & 2.71 & 1.63 & 3018.85 & 11.33 & 39.85 \\
\hline \multicolumn{7}{|c|}{ Разрез 14 - 11 Д. (Сосновый лес, пройденный верховым пожаром) } \\
\hline $\mathrm{W}(0-1)$ & 0.67 & 2.62 & - & - & - & - \\
\hline $\mathrm{C} \cdot \mathrm{f}(1-8)$ & 0.48 & 2.76 & 1.31 & 923.29 & 44.14 & 52.54 \\
\hline $\mathrm{C} 1{ }^{*}(8-41)$ & 0.36 & 2.58 & 1.36 & 1093.62 & 30.29 & 47.29 \\
\hline $\mathrm{C} 2{ }^{*}(41-102)$ & 0.18 & 2.61 & 1.53 & 2272.1 & 17.53 & 41.38 \\
\hline
\end{tabular}

Очевидно, причиной уплотнения послужило формирование гумусового горизонта, активизация процессов гумусообразования, выветривания и миграции илистой фракции и железа вниз в подгумусовый горизонт.

В соответствии с плотностью сложения, поверхностные горизонты имеют большую порозность, а в минеральных - этот показатель ниже. 
Максимальная порозность характерна для поверхностного горизонта почвы леса, пройденного низовым пожаром, что обусловлено образованием гумусового горизонта.

Водопроницаемость нетронутой пожаром почвы до глубины 33 см составляет 236.8-225.0 мм/час, что характеризуется как средняя [Воробьева, 1998]. В горизонте С' и C" она возрастает до величин 998.2 мм /час (высокая) и 1570.6 мм/час (очень высокая), что обусловлено увеличением содержания крупнодисперсных фракций с глубиной. Водоудерживающая способность соответственно достаточно высока в слаборазвитом гумусовом горизонте $(37.54 \%)$, и в песчаных горизонтах $\mathrm{C}{ }^{*}$ f и $\mathrm{C} 1{ }^{*}$ f она снижается до $17-18 \%$. Характерной чертой этой почвы является наличие мощной лесной подстилки, наименьшая влагоемкость которой более $100 \%$.

В почве, трансформированной низовым пожаром, влага удерживается гумусовым горизонтом в количестве $35.51 \%$. В минеральных горизонтах этот показатель весьма низок. Водопроницаемость средняя только гумусовом горизонте, а в минеральных горизонтах она возрастает от высокой до исключительно высокой.

После верхового пожара водоудерживающая способность почвы имеет повышенные значения, очевидно в связи с активизацией метаморфических процессов, однако водопроницаемость, при отсутствии признаков гумусонакопления остается «высокой» и «исключительно высокой».

Таким образом, после пожаров несколько увеличивается водоудерживающая способность почвы и водопроницаемость, создавая условия для активизации почвообразовательных процессов.

Физико-химические свойства. Естественные почвы сосновых боров характеризуются кислой реакцией среды (табл. 3). В поверхностных горизонтах рН имеет величину 4.8 .

Наиболее кислая реакция характерна для почвы, пройденной верховым пожаром. Непосредственно после пожара обычно происходит снижение кислотности [Щербаков и др., 1979], однако за 15 лет после верхового пожара почвы восстановили кислую реакцию. После низового пожара пониженная кислотность сохранилась в нижней части подстилки и в гумусовом горизонте.

Содержание гумуса среди аккумулятивных горизонтов максимально в корочке, сформированной на поверхности почвы, трансформированной верховым пожаром и составляет $4.4 \%$. Однако в связи с ее маломощностью запасы гумуса остаются небольшими. Во вновь сформировавшемся 
аккумулятивном горизонте почвы, трансформированной низовым пожаром, содержание гумуса относительно высокое и составляет $3.4 \%$ при мощности горизонта 6 см. Содержание гумуса имеет повышенные значения до глубины 60 см, что может быть обусловлено нисходящей миграцей подвижных форм гумуса в условиях активизации гумусообразования и кислой реакции среды. Подтверждением этому служит отношение Сгк/Сфк, которое в горизонте AYpir составляет 1,16, в подгумусовом горизонте - 0,63 и на глубине 37-60 см - 0,26.

Таблица 3

\section{Физико-химические свойства почв}

\begin{tabular}{|c|c|c|c|c|c|c|c|c|c|c|}
\hline \multirow[t]{2}{*}{$\begin{array}{l}\text { Горизонт, } \\
\text { глубина, см }\end{array}$} & \multirow[t]{2}{*}{$\begin{array}{c}\mathrm{pH}_{\mathrm{K}} \\
\mathrm{Cl}\end{array}$} & \multirow{2}{*}{$\begin{array}{c}\text { Гу- } \\
\text { мус, } \\
\%\end{array}$} & \multirow[t]{2}{*}{$\frac{\mathrm{C}_{\text {гК }}}{\mathrm{C} \phi \kappa}$} & \multicolumn{2}{|c|}{$\begin{array}{c}\text { Запасы гу- } \\
\text { муса, } \\
\text { т/г }\end{array}$} & \multicolumn{3}{|c|}{$\begin{array}{c}\text { Обменные осно- } \\
\text { вания. гидролити- } \\
\text { ческая кислот- } \\
\text { ность, мг`экв/100 г }\end{array}$} & \multirow{2}{*}{$\begin{array}{l}\text { ЕКО, } \\
\frac{\mathrm{M} \cdot \cdot \mathrm{F}}{\underline{\mathrm{B}}} \\
100 \text { Г }\end{array}$} & \multirow[t]{2}{*}{$\begin{array}{l}\mathrm{CHO} \\
\% \\
\%\end{array}$} \\
\hline & & & & $\mathrm{a}$ & 6 & $\mathrm{Ca}^{2}$ & $\mathrm{Mg}^{2+}$ & $\mathrm{H}^{+}$ & & \\
\hline \multicolumn{11}{|c|}{$\begin{array}{c}\text { Разрез 15-11 Д } \\
\text { (Сосновый лес, без признаков пирогенеза) }\end{array}$} \\
\hline $\mathrm{O}(0-4)$ & 4.8 & $15.0^{*}$ & - & - & - & 6.2 & 3.1 & 48.1 & 57.4 & 16 \\
\hline We (4-9) & 4.8 & 1.7 & 0,52 & 10,4 & \multirow{4}{*}{16,8} & 3.1 & 1.2 & 3.48 & 7.78 & 55 \\
\hline 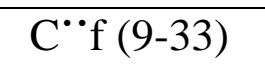 & 4.9 & 0.03 & - & 1,0 & & 2.2 & 0.2 & 1.82 & 4.22 & 56 \\
\hline $\mathrm{C} 1{ }^{\circ}{ }^{\circ} \mathrm{f}(33-70)$ & 5.1 & 0.09 & - & 4,6 & & 2.1 & 0.8 & 1.23 & 4.13 & 70 \\
\hline $\mathrm{C} 2{ }^{*} \cdot(70-110)$ & 5.1 & - & - & $0,8^{* *}$ & & 1.7 & 1.0 & 0.95 & 3.65 & 73 \\
\hline \multicolumn{11}{|c|}{$\begin{array}{c}\text { Разрез 13-11Д } \\
\text { (Сосновый лес, пройденный низовым пожаром) }\end{array}$} \\
\hline O1 (0-1) & 4.6 & $64.2^{*}$ & - & - & - & 6.0 & 1.2 & 44.9 & 52.1 & 13 \\
\hline $\mathrm{O} 2(0-2)$ & 5.0 & $62.4^{*}$ & - & - & - & 6.0 & 0.5 & 19.1 & 25.6 & 25 \\
\hline AY (2-8) & 5.1 & 3.4 & 1,16 & 21,8 & \multirow{4}{*}{66,4} & 5.0 & 0.6 & 4.42 & 10.02 & 55 \\
\hline$C \cdot \cdots(8-37)$ & 4.7 & 0.41 & 0,63 & 19,1 & & 1.6 & 0.3 & 2.74 & 4.64 & 40 \\
\hline $\mathrm{C} 1{ }^{\circ}(37-60)$ & 4.9 & 0.55 & 0,26 & 19,9 & & 1.6 & 0.3 & 1.20 & 3.1 & 61 \\
\hline $\mathrm{C} 2{ }^{*}(60-112)$ & 5.3 & 0.09 & - & $5,7 * *$ & & 1.2 & 1.0 & 0.97 & 3.17 & 69 \\
\hline \multicolumn{11}{|c|}{$\begin{array}{c}\text { Разрез 14-11 Д } \\
\text { (Сосновый лес, пройденный верховым пожаром) }\end{array}$} \\
\hline $\mathrm{W}(0-1)$ & 4.4 & 4.4 & 0,63 & 5,3 & \multirow{4}{*}{28,5} & 2.0 & 1.0 & 6.69 & 9.69 & 30 \\
\hline $\mathrm{C}^{*} \cdot \mathrm{f}(1-8)$ & 4.8 & 0.6 & 0,58 & 5,5 & & 1.6 & 0.8 & 2.52 & 4.92 & 48 \\
\hline $\mathrm{C} 1{ }^{\circ}(8-41)$ & 4.9 & 0.2 & - & 8,9 & & 1.6 & 0.6 & 1.34 & 3.54 & 62 \\
\hline $\mathrm{C} 2{ }^{*} \cdot(41-102)$ & 5.1 & - & - & $8,9 * *$ & & 1.7 & 1.0 & 0.91 & 3.61 & 74 \\
\hline
\end{tabular}

Примечание * - Сорг; **- до 1 м; Запасы гумуса: а - по горизонтам; б - в слое 1 м. 
Возможно, в гумусовом горизонте в состав гуминовых кислот попадает пирогенный углерод. А.П. Чевычеловым показано, что в условиях влияния пирогенеза в лесах Якутии происходит смена типа гумуса либо в сторону оподзоливания, либо - буроземообразования. Также отмечается задержка развития коры выветривания на стадии феррсиаллитного элювия при одновременном широком формировании неоподзоленных альфегумусовых почв [Чевычелов, 1997, 2002].

В почве после верхового пожара содержание гумуса относительно высокое только в корочке, в подгумусовом горизонте до глубины $8 \mathrm{~cm}$ этот показатель значительно ниже - 0,6\%. Состав гумуса в горизонтах W и $\mathrm{C}$ •*f гуматно-фульватный. Запасы гумуса в метровом слое пирогенных почв по сравнению с фоновыми возрастают: после низового пожара в 4 раза, а после верхового - в 1,7 раз, что может быть обусловлено как активизацией гумусообразования, так и присутствием пирогенного углерода. Увеличение содержания гумуса в почвах после низовых пожаров в Байкальском регионе показаны И.А. Платоновой и Г.А. Ивановой [Платонова, Иванова, 2014]. Авторы считают это одной из причин активного возобновления сосновых лесов. Некоторые авторы отмечают улучшение свойств почв после низовых пожаров и рекомендуют проводить профилактические выжигания [Федоров, Тарасов, 2013, Kumar и др.,2013].

Максимальные значения емкости катионного обмена (ЕКО) характерны для поверхностных в различной степени гумусированных горизонтов. В минеральных горизонтах этот показатель резко снижается. В содержании обменных оснований наибольшие показатели характерны для почвы, измененной низовым пожаром. Сумма их составляет в горизонте AY - 6.6 мг-экв/100 г почвы. В непирогенной почве эта величина ниже 4.3 мг-экв/100 г почвы. В маломощном аккумулятивном горизонте почвы, измененной верховым пожаром, этот показатель минимален (3.0 мгэкв/100 г почвы). Показатель гидролитической кислотности имеет наибольшие значения в горизонтах подстилки псаммоземов, где он достигает величины 45 - 48 мг-экв/100 г почвы. Степень насыщенности основаниями минимальна (CHO) в лесных подстилках, несколько повышается в аккумулятивных горизонтах. Для почвообразующей породы характерна насыщенность 61 - 74\%, что свидетельствует о кислом характере почвообразования, накладывающемся на ненасыщенную основу. 
По результатам исследования были сделаны следующие выводы.

1. Под сосновыми борами Селенгинского дельтового района формируются псаммоземы гумусовые оподзоленные, профиль которых состоит из мощной подстилки и слабо развитого гумусово-аккумулятивного горизонта с признаками осветления. Почвы характеризуются кислой реакцией среды по всему профилю, ненасыщенностью основаниями, низким содержанием гумуса.

2. Низовые пожары приводят к формированию пирогенных горизонтов подстилки и гумусово-аккумулятивного горизонта, отличающихся темной окраской и присутствием углистых веществ. Под влиянием низового пожара происходит снижение кислотности, увеличение содержания и запасов гумуса и суммы обменных оснований. Учитывая особенности строения и свойств почвы предлагается название: «псаммозем гумусовый постпирогенный».

3. В результате верховых пожаров отмечается сосредоточенность признаков почвообразования в маломощном прерывистом (1см) горизонте $\mathrm{W}$, снижение мощности толщи, обогащенной физической глиной, очень низкое содержание фракции крупной пыли в подгумусовом горизонте свидетельствуют о послепожарном развитии почвы в условиях активизации процессов дефляции. Почва характеризуется низкими $\mathrm{pH}$, показателями содержания обменного кальция и степени насыщенности основаниями. Роль сорбента в горизонте играют остатки лишайника, аккумулирующие на поверхности дисперсные частицы. Отмечается относительно высокое содержание гумуса гуматно-фульватного состава в поверхностной корочке. Строение и признаки почвы соответствуют типу «псаммозем гумусовый иллюиально-ожелезненный».

4. Общий для всех почв альфегумусовый процесс проявляется слабо в связи с континентальностью климата, жестким ветровым режимом, быстрой прогреваемостью песчаных почв и низкой водоудерживающей способностью; развитие почв задерживается на стадии слаборазвитых.

5. Полученные материалы свидетельствуют о необходимости исследования трансформации углистых веществ и их сорбционной способности в процессе послепожарного развития почв, а также трансформации форм соединений железа при пожаре и дальнейшем поведении и их роли в развитии почв. 


\section{Литература}

1. Воробьев Ю.Л. Лесные пожары на территории России: Состояние и проблемы / Ю. Л. Воробьев, В. А. Акимов, Ю. И. Соколов; Под общ.ред. Ю. Л. Воробьева; МЧС России. - М.: ДЭКС-ПРЕСС, 2004. - 312 с.

2. Воробьева Л.А. Химический анализ почв. М.: Изд-во МГУ, 1998. $272 \mathrm{c}$.

3. Гынинова А.Б., Корсунов В.М. Почвы Селенгинского дельтового района. // Почвоведение. 2006. №3.С. 273-281.

4. Гынинова А.Б., Балсанова Л.Д., Халюева Т.И., Убугунова В.И., Гынинова Б.Д. Водоохранные функции почв дельты р. Селенги. // Вестник БГУ. 2006. №3. С. 24-33.

5. Жуков В.М. Климат Бурятской АССР. Улан-Удэ: Бурят. кн. издво, 1960. $188 \mathrm{c}$.

6. Итоги пожароопасного сезона 2014 года на территории Республики Бурятия задачи на 2015 год. http:/www.alh-rb.ru/press/presentations.

7. Качинский Н.А. Физика почв. Ч. 1. М.: «Высшая школа», 1965. $323 \mathrm{c}$.

8. Классификация и диагностика почв России / под ред. Г.В. Добровольского. Смоленск: Ойкумена, 2004. 342 с.

9. Платонова И.А., Иванова Г.А. Оценка естественного возобновления после низовых пожаров в сосняках Селенгинского среднегорья // Вестник КрасГАУ. 2014. № 8. С. 168-175.

10. Щербаков И.П., Забелин О.Ф., Карпель Б.А. и др. Лесные пожары в Якутии и их влияние на природу леса. Новосибирск: Наука. Сиб. отд-ние, 1979. 224 с.

11. Федеральный закон «Об охране озера Байкал». №94. - Ф3 от 01.05. 1999.

12. Федоров П.В., Тарасов П.А. О пирогенном влиянии на физикохимические характеристики почвы // Молодые ученые в решении актуальных проблем науки. Красноярск, 2013. Т. 1. С.3-5.

13. Чевычелов А.П. Пирогенез и зональное таежное континентальное автоморфное почвообразование на северо-востоке Азии (на примере Южной Якутии): автореф. дис.... докт. биол. наук: 03.00.27. Новосибирск, $1997.33 \mathrm{c}$.

14. Чевычелов А.П. Пирогенез и постпирогенные трансформации свойств и состава мерзлотных почв // Сиб. экол. журн. 2002. №3. С. 273-277. 
15. Kumar M., Sheikh M.A., Bhat J.A, Bussmann R.W. Effect of fire on soil nutrients and understorey vegetation in Chir pine forest in Garhwal Himalaya, India // ActaEcologicaSinica. 2013. Vol. 33, I.1. P. 59-63 